\title{
Comparative Analysis of Biodentine, Calcium Hydroxide, and 2\% Chlorhexidine with Resin-modified Glass Ionomer Cement as Indirect Pulp Capping Materials in Young Permanent Molars
}

\author{
Shalan Kaul ${ }^{1}$, Ajay Kumar ${ }^{2}$, Ankush Jasrotia ${ }^{3}$, Kamna Gorkha ${ }^{4}$, Stuti Kumari ${ }^{5}$, Sumaya Y Jeri ${ }^{6}$
}

\begin{abstract}
Aim and objective: This study was carried out to compare the effectiveness of biodentine, calcium hydroxide, and $2 \%$ chlorhexidine gluconate used along with resin-modified glass ionomer cement (RMGIC) as indirect pulp capping (IPC) materials in young permanent molars.

Materials and methods: In this study, 54 patients were selected. Among these patients, 72 young permanent molars were selected randomly in which IPC was required. These teeth were randomly categorized into three different groups and each group consisted of 24 teeth. The first group was group A consisting of teeth treated with biodentine, the second group was group B consisting of teeth treated with $2 \%$ chlorhexidine gluconate being followed by RMGIC, while the third was group C consisting of teeth treated with calcium hydroxide. All cases were subjected to follow-up for clinical and radiographic evaluation at 4, 8, and 16 months. The data were recorded and analyzed statistically by utilizing the Chi-square test.

Results: After 16 months, $95.83 \%$ of cases in group A consisting of teeth treated with biodentine showed successful results both clinically and radiographically. While $87.5 \%$ of cases in group B consisting of teeth treated with $2 \%$ chlorhexidine gluconate being followed by RMGIC showed successful results. And finally, $91.66 \%$ of cases in group C consisting of teeth treated with calcium hydroxide showed successful results. Conclusion: Biodentine can be efficiently used as an IPC agent in young permanent molars although all three materials were effective in IPC with a nonsignificant difference statistically. This study highlights the success of IPC in young permanent molars and the choice of better IPC material can be biodentine.

Clinical significance: Indirect pulp capping is one of the procedures in which preservation of carious affected dentin nearest to the pulp is carried out to protect the pulp. Several new IPC agents like biodentine have been introduced. Hence, it is necessary to evaluate their effectiveness.

Keywords: Biodentine, Calcium hydroxide, Indirect pulp capping, Resin-modified glass ionomer cement.

The Journal of Contemporary Dental Practice (2021): 10.5005/jp-journals-10024-3084
\end{abstract}

\section{INTRODUCTION}

Vital pulp treatment (VPT) is a procedure carried out to protect and preserve pulp tissue that has been damaged but has not been destroyed by conditions such as carious tooth, physical trauma, and invasive restorative procedures. This is quite significant for management of teeth in young patients where development of an apical portion of the root is incomplete. ' Indirect pulp capping (IPC) is one of the main processes of vital pulp therapy. It is a method in which preservation of affected carious dentin nearest to the pulp is carried out to prevent the exposure of the pulp. Then this layer of dentin is covered with a material that helps in formation of reparative dentin and protection of pulp. ${ }^{2}$ Several studies in recent times have shown that there is a huge success in preservation of young permanent teeth after carrying out IPC. The average success rate has been around 90\%. Moreover, there are fewer chances of negative outcomes both clinically and radiographically. ${ }^{3}$

Conventionally the most commonly used material in IPC is calcium hydroxide. This has been due to the alkaline $\mathrm{pH}$ of calcium hydroxide and its biocompatible nature that signals remineralization at the junction of pulp and dentine. ${ }^{4}$ A very important drawback of calcium hydroxide is an increased chance of solubility due to less adhesive properties with dentin. ${ }^{5}$ As a result some materials like resin-modified glass ionomer cement (RMGIC) that have additional adhesive properties have been introduced. ${ }^{6}$ It has been found that RMGIC are effective as IPC agents in adverse conditions such as

\begin{abstract}
1,4 Department of Pedodontics and Preventive Dentistry, Indira Gandhi Government Dental College and Hospital, Jammu, Jammu and Kashmir, India

${ }^{2,3}$ Department of Conservative Dentistry and Endodontics, Indira Gandhi Government Dental College and Hospital, Jammu, Jammu and Kashmir, India

${ }^{5}$ Department of Dentistry, Sri Krishna Medical College and Hospital, Muzaffarpur, Bihar, India

${ }^{6}$ Department of Orthodontics and Dentofacial Orthopedics, ITS Dental College and Hospital, Ghaziabad, Uttar Pradesh, India

Corresponding Author: Ajay Kumar, Department of Conservative Dentistry and Endodontics, Indira Gandhi Government Dental College and Hospital, Jammu, Jammu and Kashmir, India, Phone: +91 9469214385, +91 7006241064, e-mail: drajaygupta123@gmail.com

How to cite this article: Kaul S, Kumar A, Jasrotia A, et al. Comparative Analysis of Biodentine, Calcium Hydroxide, and 2\% Chlorhexidine with Resin-modified Glass lonomer Cement as Indirect Pulp Capping Materials in Young Permanent Molars. J Contemp Dent Pract 2021;22(5):511-516.
\end{abstract}

Source of support: Nil

Conflict of interest: None

minimum thickness of remaining dentin in teeth severely damaged by large carious lesions. Such an effect of RMGIC can be attributed to their additional adhesive properties with dentin and their 
antimicrobial properties. ${ }^{7}$ A new development in recent times is the use of chemical antiseptic namely chlorhexidine gluconate (CG). It is believed to be an important aspect of antimicrobial therapy of the oral cavity as it is commonly used as an irrigation system and intracanal medical agent. ${ }^{8}$

Recently, a new bioactive material called biodentine has been introduced as an artificial substitute to dentin. This new material has several additional features like resistance to microleakage in restoration of large carious tooth resulting in minimal sensitivity observed postoperatively. Biodentine also helps in increasing the mineral deposition and the density of bridge between pulp and dentine. It was observed that biodentine is no less than glass ionomer cements in terms of sealing property. But it has added advantage that there is no need for dentin conditioning as observed in the case of GIC treated cases. ${ }^{9}$

Keeping in mind the better characteristics of biodentine, the current study was carried out to compare biodentine, calcium hydroxide, and $2 \%$ chlorhexidine gluconate with RMGIC as IPC materials in young permanent molars.

\section{Materials and Methods}

In this study, 54 young adult patients aged between 12 years and 18 years reporting to the outpatient department of Indira Gandhi Government Dental College and Hospital, Jammu were selected. Informed consent regarding the study was obtained from the patients' guardians. Clearance was obtained from ethical committee. The study was extended from January 2019 to June 2020. Only healthy subjects with no systemic disorder were included. The study sample included young permanent molars in which there were deep caries that were closer to the pulp.

Moreover, only those subjects were selected who did not gave a history of spontaneous tooth pain and there was no tenderness observed on palpation and percussion. The radiographic criterion for the selection of subjects was the presence of deep caries approaching pulp but the lamina dura was intact and there was no root resorption. Among these patients, 72 young permanent molars were selected randomly in which IPC was required. These teeth were randomly categorized into three different groups and each group consisted of 24 teeth. The first group was group A consisting of teeth treated with biodentine (Septodont, Mumbai, India), the second group was group B consisting of teeth treated with $2 \%$ chlorhexidine gluconate being followed by RMGIC (GC Fuji II LC, Tokoyo, Japan), while the third group was group C consisting of teeth treated by calcium hydroxide (Dycal, Mumbai, India). All cases were subjected to follow-up for clinical and radiographic evaluation at 4,8 , and 16 months.

\section{Treatment Procedure}

\section{First Appointment}

First of all, there was a complete clinical and radiographic evaluation of the selected teeth. After that, there was an administration of local anesthesia using $2 \%$ lignocaine for the teeth which were to be operated. A rubber dam was placed. Rinsing of the cavity was done with water and then it was air-dried. After that caries indicator (Ultradent Sable Seek) was put in the cavity prepared to distinguish between the infected dentin and the affected dentin. Areas showing affected dentin were not removed while that of infected dentin was removed. All the cavities were treated by a single clinician along with two assistants.

In group $A$, the liquid of biodentine was added to powder of capsule according to the manufacturers' instructions. After that, there was a trituration for $30 \mathrm{~s}$. The mixture obtained after trituration was then put in the prepared cavity (Fig. 1). The material was placed up to the occlusal level and then adjustment was made at the occlusal level. Then in group B, first of all, there was placement of $2 \%$ chlorhexidine gluconate over the base of prepared cavity for $60 \mathrm{~s}$. After this, there was a proper placement of liner of RMGIC into the cavity followed by light curing for $60 \mathrm{~s}$. Finally, the entire cavity was restored with composite in increments (Fig. 2). Finally in group C, there was placement of calcium hydroxide over the base of cavity which was followed by placement of liner of GIC. Then cavity was completely restored with composite (Fig. 3). It was taken proper care that a radiograph was taken in every group after the clinical procedure.

\section{Second Appointment}

After 4 months, there was an evaluation of the subjects clinically. After that, some adjustment was made in the teeth treated with
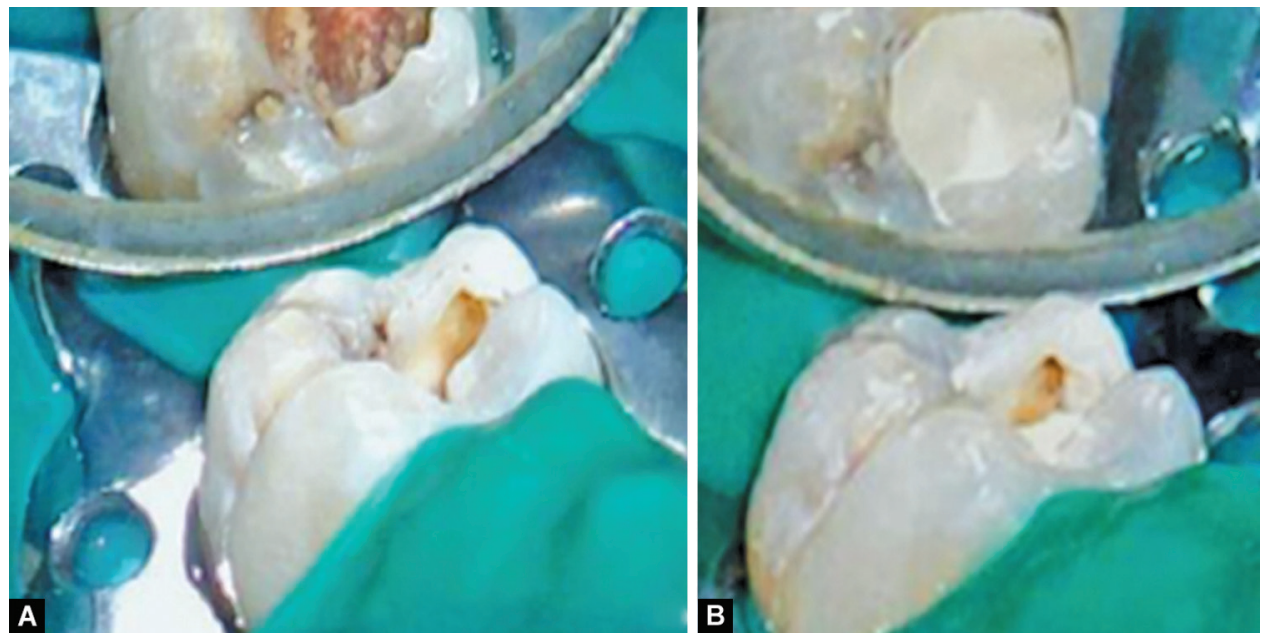

Figs 1 A and B: (A) Preparation of the floor of cavity for placement of biodentine; (B) Biodentine placement at the floor of the cavity after preparation of floor of cavity 

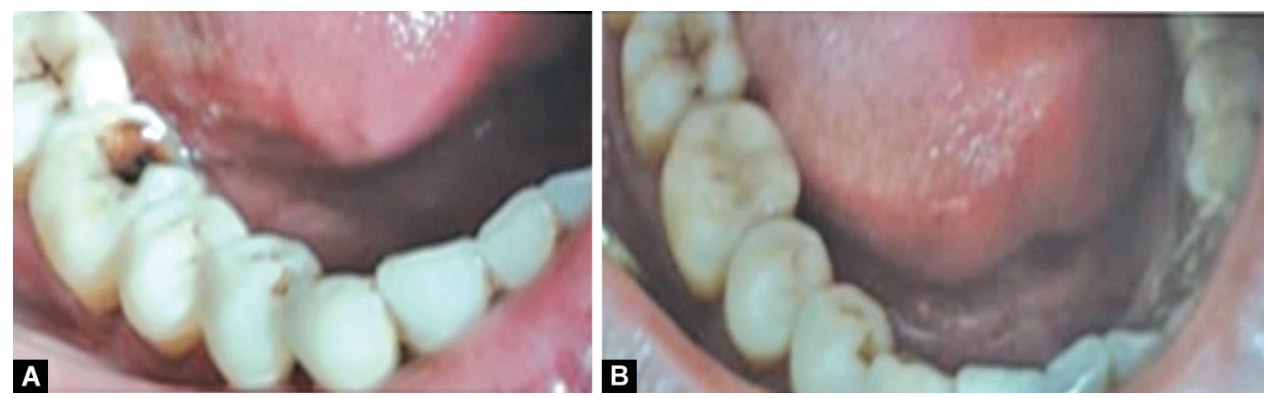

Figs $2 \mathrm{~A}$ and B: (A) Pretreatment with RMGIC; (B) Posttreatment with RMGIC
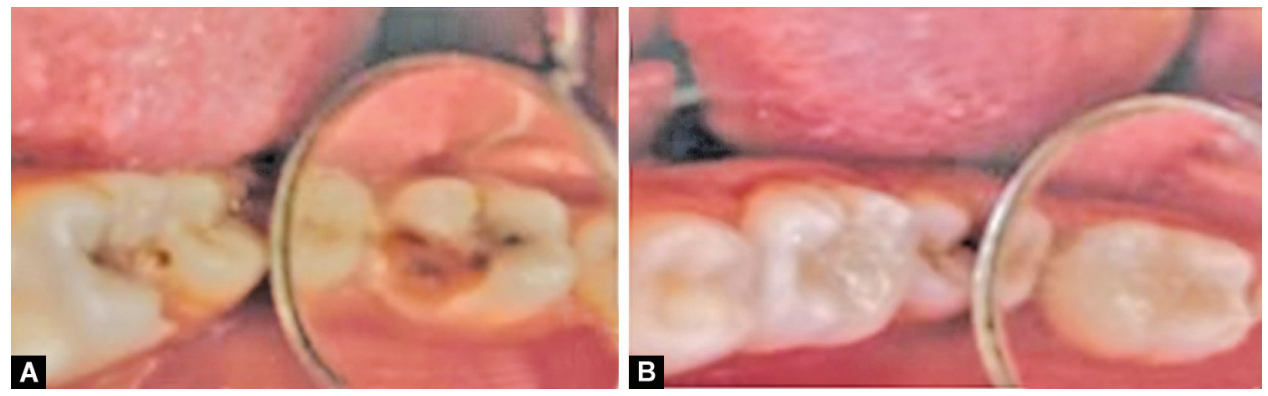

Figs 3A and B: (A) Pretreatment with calcium hydroxide; (B) Posttreatment with calcium hydroxide

biodentine in group A. In the first appointment, the cavity was completely filled with biodentine. In the second appointment, there is removal of biodentine such that it is present at the base only. Then there was an etching of the base material for $15 \mathrm{~s}$. It was rinsed with water and then air-dried. Then there was an application of bonding agent followed by complete restoration of the cavity with composite.

\section{Follow-up}

The patients belonging to all the groups were recalled at 4, 8 , and 16 months. At each follow-up, there was complete analysis focusing on the clinical history, proper clinical and radiological examination. Clinical examination also included recording the response of treated teeth to cold and hot stimuli. Teeth were considered radiographically normal when the lamina dura was intact, there was no root resorption and there was an absence of periapical radiolucency. Treatment was considered a failure when there were features suggestive of irreversible pulpitis or tooth necrosis either clinically or radiographically present. In such cases where there was a failure of IPC, proper endodontic procedure was carried out. The data was recorded and the Chi-square test was used for statistical analysis.

\section{Results}

In group A, all 24 teeth showed successful results both clinically and radiographically at 4 months and 8 months follow-up. However, at 16 months follow-up it was found that one tooth developed pain and swelling at the adjacent soft tissues suggestive of treatment failure. The same tooth showed a radiographic failure of treatment. However, that tooth was clinically and radiographically normal at 4 months and 8 months follow-up. Then the proper endodontic procedure was carried out to treat that tooth. Overall the success percentage was $100 \%$ at 4 months and 8 months follow-up while it was $95.83 \%$ at 16 months follow-up (Table 1, Fig. 4).

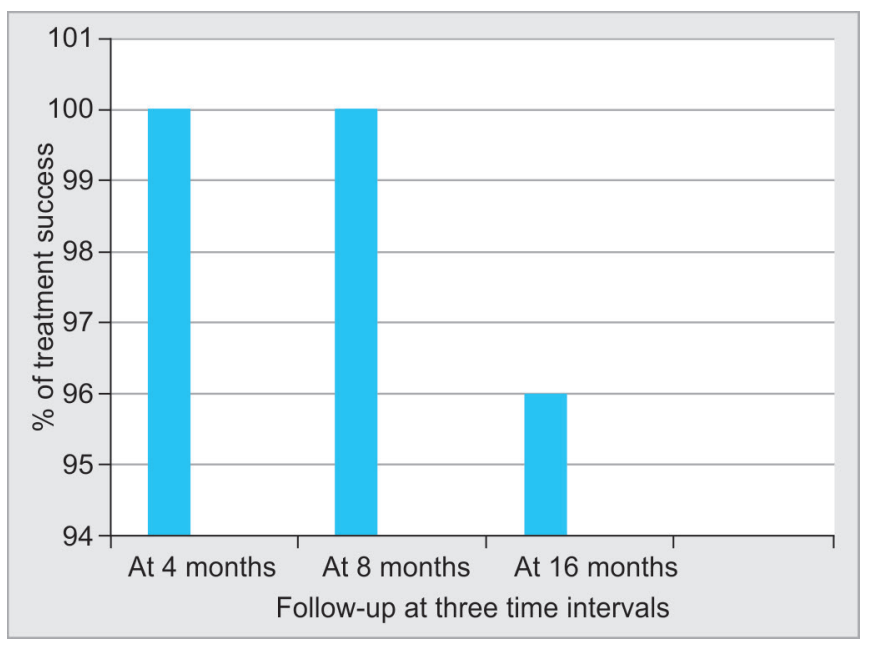

Fig. 4: Data showing the success and failures of IPC with biodentine on follow-up at different time intervals

In group B, 23 teeth showed successful results. However, one tooth developed pain and a further increase in the decay of tooth suggestive of treatment failure. That tooth showed the failure of treatment radiographically also. The tooth was subjected to further endodontic treatment. The study was continued on remaining 23 teeth. At 8 months follow-up 22 teeth out of 23 teeth showed successful results. However, one tooth again developed pain and swelling suggestive of treatment failure. Adequate endodontic treatment was performed for that tooth also. Now the sample size got reduced to 22 teeth. At 16 months follow-up 21 teeth out of 22 teeth showed successful results while again one tooth was found to show a failure of treatment. Overall the success percentage was $95.83 \%$ at 4 months follow-up, $91.66 \%$ at 8 months follow-up, and $87.5 \%$ at 16 months follow-up (Table 1, Fig. 5). 
Indirect Pulp Capping Materials in Young Permanent Molars

Table 1: Data showing the success and failures of indirect pulp capping (IPC) with biodentine, resin-modified glass ionomer cement (RMGIC), and calcium hydroxide on follow-up at different time intervals

\begin{tabular}{|c|c|c|c|c|c|c|c|c|c|}
\hline & \multicolumn{3}{|c|}{ Group A: biodentine } & \multicolumn{3}{|c|}{ Group B: RMGIC } & \multicolumn{3}{|c|}{ Group C: calcium hydroxide } \\
\hline & 4 months & 8 months & 16 months & 4 months & 8 months & 16 months & 4 months & 8 months & 16 months \\
\hline$n$ & 24 & 24 & 23 & 24 & 23 & 22 & 24 & 24 & 23 \\
\hline $\begin{array}{l}\text { Successful } \\
\text { clinically }\end{array}$ & 24 & 24 & 23 & 23 & 22 & 21 & 24 & 23 & 22 \\
\hline $\begin{array}{l}\text { Successful } \\
\text { radiographically }\end{array}$ & 24 & 24 & 23 & 23 & 22 & 21 & 24 & 23 & 22 \\
\hline $\begin{array}{l}\text { Unsuccessful } \\
\text { clinically }\end{array}$ & 00 & 00 & 01 & 01 & 01 & 01 & 00 & 01 & 01 \\
\hline $\begin{array}{l}\text { Unsuccessful } \\
\text { radiographically }\end{array}$ & 00 & 00 & 01 & 01 & 01 & 01 & 00 & 01 & 01 \\
\hline $\begin{array}{l}\text { Percentage of } \\
\text { success }\end{array}$ & 100 & 100 & 95.83 & 95.83 & 91.66 & 87.5 & 100 & 95.83 & 91.66 \\
\hline
\end{tabular}

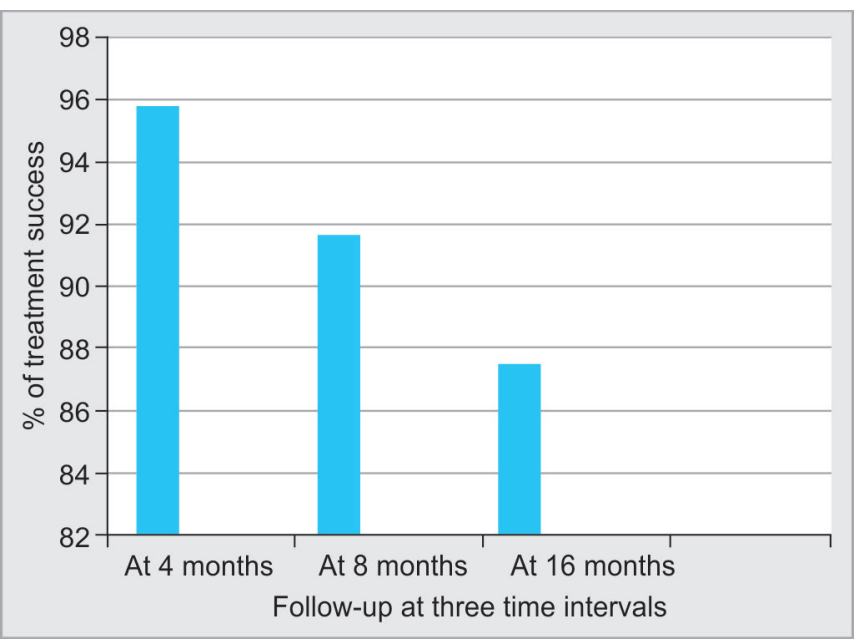

Fig. 5: Data showing the success and failures of IPC with RMGIC on follow-up at different time intervals

In group C, all 24 teeth showed successful results both clinically and radiographically at 4 months follow-up. At 8 months follow-up 23 teeth showed successful results as one tooth developed pain and pus discharge suggestive of treatment failure. The sample size of the study got reduced to 23 . At 16 months follow-up 22 teeth out of 23 teeth showed successful results while again one more tooth was diagnosed to be grossly decayed tooth showing failure of treatment. Overall the success percentage was $100 \%$ at 4 months follow-up, $95.83 \%$ at 8 months follow-up, and $91.66 \%$ at 16 months follow-up (Table 1, Fig. 6).

A Chi-square test was used for statistical analysis. The Chi-square and $p$-value obtained were 2.03 and 0.354 , respectively at 4 months and it was 2.02 and 0.344 , respectively at 16 months follow-up which specifies that all three materials were effective in IPC with not much difference. However, biodentine was proved to be more successful clinically and radiographically (Table 2).

\section{Discussion}

In the current study, all three IPC materials were effective in IPC with no statistically significant difference. However, biodentine

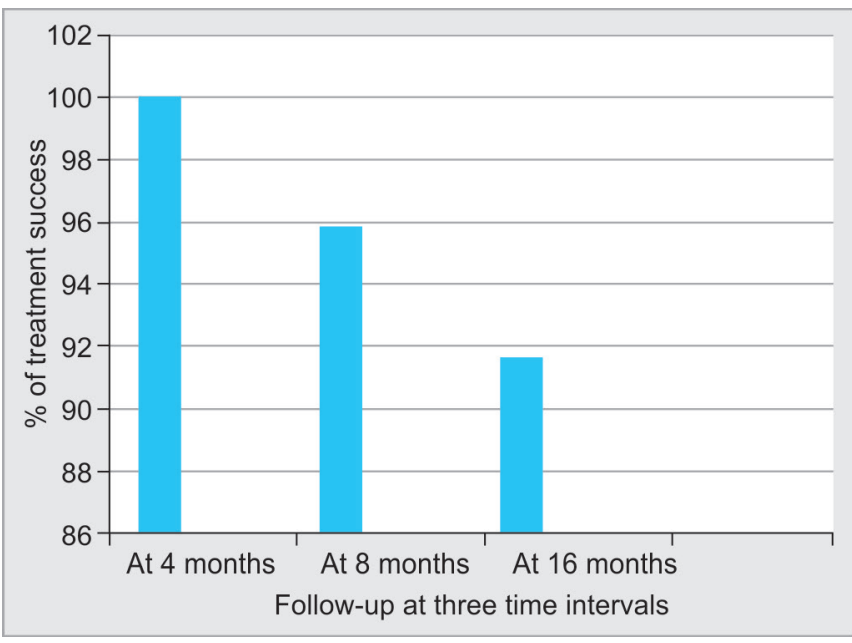

Fig. 6: Data showing the success and failures of IPC with calcium hydroxide on follow-up at different time intervals

was proved to be more successful as an IPC agent. Hirschman et al. and Nowicka et al. conducted a study in which biodentine was used as IPC material and found that biodentine was quite effective in IPC..$^{10,11}$ Soliman et al. also conducted a study in young permanent teeth and found that the success rate was $100 \%$ when biodentine was used as an IPC agent. ${ }^{12}$ Conducted a study in which they analyzed the response of pulpal tissue in primary teeth when biodentine was used as IPC agent after 7, 28, and 90 days. The results obtained from the study conducted by concluded that biodentine possesses bioactive properties, and it causes regeneration of dentinal tissue and there is no inflammatory response in the pulpal tissue. ${ }^{12}$

Good results were also reported when calcium hydroxide was used as an IPC agent in this study with very few cases showing failure of treatment. Similar results were found when Falster et al. conducted a study and obtained good results with calcium hydroxide as an IPC agent. ${ }^{13} \mathrm{Al}$-Zayer et al. conducted a study in primary molars from 2 weeks to 73 weeks and found that $95 \%$ of cases showed successful results when treated with calcium hydroxide as IPC agent. $^{14}$ 
Table 2: Statistical data at follow-up

\begin{tabular}{|c|c|c|c|c|c|c|}
\hline & \multicolumn{2}{|c|}{4 months } & \multicolumn{2}{|c|}{8 months } & \multicolumn{2}{|c|}{16 months } \\
\hline & $\begin{array}{l}\text { Successful } \\
\text { cases }\end{array}$ & $\begin{array}{l}\text { Unsuccessful } \\
\text { cases }\end{array}$ & $\begin{array}{l}\text { Successful } \\
\text { cases }\end{array}$ & $\begin{array}{l}\text { Unsuccessful } \\
\text { cases }\end{array}$ & $\begin{array}{l}\text { Successful } \\
\text { cases }\end{array}$ & $\begin{array}{l}\text { Unsuccessful } \\
\text { cases }\end{array}$ \\
\hline $\begin{array}{l}\text { Group A: Teeth } \\
\text { treated with } \\
\text { biodentine }\end{array}$ & 24 & 00 & 24 & 00 & 23 & 01 \\
\hline $\begin{array}{l}\text { Group B: Teeth } \\
\text { treated with } \\
\text { RMGIC }\end{array}$ & 23 & 01 & 22 & 01 & 21 & 01 \\
\hline $\begin{array}{l}\text { Group C: } \\
\text { Teeth treated } \\
\text { with calcium } \\
\text { hydroxide }\end{array}$ & 24 & 00 & 24 & 01 & 22 & 01 \\
\hline$X^{2}$ & \multicolumn{2}{|r|}{2.03} & \multicolumn{2}{|c|}{2.05} & \multicolumn{2}{|r|}{2.02} \\
\hline$p$-value & \multicolumn{2}{|c|}{0.354} & \multicolumn{2}{|c|}{0.367} & \multicolumn{2}{|c|}{0.344} \\
\hline
\end{tabular}

In this study, IPC with RMGIC with $2 \%$ chlorhexidine also showed successful results. Similar results of the success of IPC were reported by Mickenautsch et al. and Hayashi et al. ${ }^{15,16}$ Marchi et al. conducted a study in primary teeth and found that $93 \%$ of cases were successfully treated using RMGIC as IPC agents. ${ }^{17}$ Similarly Farooq et al. conducted another study and concluded that on applying RMGIC as an IPC agent in primary teeth $96.5 \%$ cases were treated successfully. ${ }^{18}$

Management of deep carious teeth is a matter of debate because there is a vast difference in treatment principles and concepts. It is very difficult to make a proper diagnosis of the condition of pulp vitality because there are many difficulties in assessment of actual clinical status of pulp. One of the most important steps in the management of deep carious teeth is to protect the vitality of pulp. If the pulp is managed conservatively then the possibility of extensive endodontic procedure can be reduced significantly. ${ }^{19}$ It is believed that there is a possibility that pulp tissue can get repaired themselves once the carious lesions are removed without pulp exposure. This conservative treatment becomes questionable once the pulp gets exposed. Besides the possibility of success of the treatment becomes reduced once the pulp gets infected and there is pulp exposure during caries removal. ${ }^{20,21}$

Indirect pulp capping is an important process of preservation of pulp vitality. It is a method in which affected dentin nearest to pulp is not removed with a purpose of prevention of pulp exposure. Then a material is used to cover this layer of affected dentin which is considered as IPC material. Indirect pulp capping is a great successful procedure in maintaining the pulp vitality in young permanent teeth as suggested by several recent studies. ${ }^{22}$ Several materials are being used for IPC and it is necessary to evaluate their effectiveness in IPC. In the current study, three different materials namely biodentine, calcium hydroxide, and RMGIC with $2 \%$ chlorhexidine were compared for their effectiveness in IPC in young permanent molars.

In the present study, biodentine was found to be a better IPC agent although the other two materials were also statistically similar in their results. It has been noticed that biodentine forms hydroxyapatite crystals at the margins due to which it provides better integrity of the margins. Generally, microleakage is responsible for infection of pulp leading to impairment of success of vital pulp therapy. This problem is not observed when biodentine is used as a pulp capping agent. It is due to the excellent sealing ability of biodentine. ${ }^{12,23}$ Calcium hydroxide acts as a pulp capping agent because there is hard tissue formation as a result of inflammatory response against the irritant nature of calcium hydroxide. But in the case of biodentine, hard tissue formation is noninflammatory as it is due to their compatibility with cell recruitment. It was stated that the necrotic layer formed as a result of calcium hydroxide appears to be larger than other bioactive materials like biodentine. ${ }^{23}$

The limitation of this study was that histological examinations were not carried out. More studies involving histological examination with longer follow-up periods and larger sample size should be conducted for better results.

\section{Conclusion}

Biodentine exhibited the highest success rate as compared with calcium hydroxide and RMGIC liner in conjunction with $2 \%$ chlorhexidine gluconate as a disinfecting solution. This study highlights the success of IPC in young permanent molars and the choice of better IPC material can be biodentine.

\section{References}

1. Ward J. Vital pulp therapy in cariously exposed young permanent teeth and its limitations. Aust Endod J 2002;28(1):29-37. DOI: 10.1111/ j.1747-4477.2002.tb00364.x.

2. Cvek M. A clinical report on partial pulpotomy and capping with calcium hydroxide in permanent incisors with complicated crown fracture. J Endod 1978;4(8):232-237. DOI: 10.1016/S00992399(78)80153-8.

3. AguilarP,LinsuwanontP.Vital pulptherapy in vital permanentteeth with cariously exposed pulp: a systematic review. J Endod 2011;37(5):581587. DOI: 10.1016/j.joen.2010.12.004.

4. Dammaschke T, Leidinger J, Schafer E. Long-term evaluation of direct pulp capping - treatment outcomes over an average period of 6.1 years. Clin Oral Investig 2010;14(5):559-567. DOI: 10.1007/ s00784- 009- 0326-9.

5. Caplan DJ, Cai J, Yin G, et al. Root canal filled versus non-root canal filled teeth: a retrospective comparison of survival times. J Public Health Dent 2005;65(2):90-96. DOI: 10.1111/j.1752-7325.2005.tb02792.x.

6. Al-Hiyasat AS, Barrieshi-Nusair KM, Al-Omari MA. The radiographic outcomes of direct pulp-capping procedures performed by dental students: a retrospective study. J Am Dent Assoc 2006;137(12):1699_ 1705. DOI: 10.14219/jada.archive.2006.0116. 
7. Seltzer S, Bender IB, Ziontz M. The dynamics of pulp inflammation: correlations between diagnostic data and actual histologic findings in the pulp. Oral Surg Oral Med Oral Pathol 1963;16:969-977. DOI: 10.1016/0030-4220(63)90201-9.

8. Tabarsi B, Parirokh M, Eghbal MJ, et al. A comparative study of dental pulp response to several pulpotomy agents. Int Endod J 2010;43(7):565-571. DOI: 10.1111/j.1365-2591.2010.01711.x.

9. Mitchell DF, Tarplee RE. Painful pulpitis; a clinical and microscopic study. Oral Surg Oral Med Oral Pathol 1960;13:1360-1370. DOI: 10.1016/0030-4220(60)90301-7.

10. Hirschman WR, Wheater MA, Bringas JS, et al. Cytotoxicity comparison of three current direct pulp-capping agents with a new bioceramic root repair putty. J Endod 2012;38(3):385-388. DOI: 10.1016/j. joen.2011.11.012.

11. Nowicka A, Lipski M, Parafiniuk $M$, et al. Response of human dental pulp capped with biodentine and mineral trioxide aggregate. J Endod 2013;39(6):743-747. DOI: 10.1016/j. joen.2013.01.005.

12. Soliman AF, Abu-Hamila NA, Ebiary MAE. Assessment of biodentine as an indirect pulp capping material in young permanent molars. Tanta Dent J 2019;16(1):1-5. DOI: 10.4103/tdj.tdj_16_18.

13. Boddeda KR, Rani CR, V Vanga NR, Chandrabhatla SK. Comparative evaluation of biodentine, $2 \%$ chlorhexidine with RMGIC and calcium hydroxide as indirect pulp capping materials in primary molars: An in vivo study. J Indian Soc Pedod Prev Dent. 2019;37(1):60-66. DOI: 10.4103/JISPPD.JISPPD 213 _17.

14. Al-Zayer MA, Straffon LH, Feigal RJ, et al. Indirect pulp treatment of primary posterior teeth: a retrospective study. Pediatr Dent 2003;25(1):29-36.
15. Mickenautsch S, Yengopal V, Banerjee A. Pulp response to resinmodified glass ionomer and calcium hydroxide cements in deep cavities: a quantitative systematic review. Dent Mater 2010;26(8): 761-770. DOI: 10.1016/j.dental.2010.03.021.

16. Hayashi M, Fujitani M, Yamaki C, et al. Ways of enhancing pulp preservation by stepwise excavation-a systematic review. J Dent 2011;39(2):95-107. DOI: 10.1016/j.jdent.2010.10.012.

17. Marchi JJ, de Araujo FB, Fröner AM, et al. Indirect pulp capping in the primary dentition: a 4 year follow-up study. J Clin Pediatr Dent 2006;31(2):68-71. DOI: 10.17796/jcpd.31.2.y4um5076341226m5.

18. Faroog NS, Coll JA, Kuwabara A, et al. Success rates of formocresol pulpotomy and indirect pulp therapy in the treatment of deep dentinal caries in primary teeth. Pediatr Dent 2000;22(4):278-286.

19. Matsuo T, Nakanishi T, Shimizu H, et al. A clinical study of direct pulp capping applied to carious-exposed pulps. J Endod 1996;22(10): 551-556. DOI: 10.1016/S0099-2399(96)80017-3.

20. Mejàre I, Cvek M. Partial pulpotomy in young permanent teeth with deep carious lesions. Endod Dent Traumatol 1993;9(6):238-242. DOI: 10.1111/j.1600-9657.1993.tb00279.x.

21. Calişkan MK. Pulpotomy of carious vital teeth with periapical involvement. Int Endod J 1995;28(3):172-176. DOI: 10.1111/j.13652591.1995.tb00293.x.

22. Teixeira LS, Demarco FF, Coppola MC, et al. Clinical and radiographic evaluation of pulpotomies performed under intrapulpal injection of anaesthetic solution. Int Endod J 2001;34(6):440-446. DOI: 10.1046/j.1365-2591.2001.00414.x.

23. Malkondu Ö, Karapinar Kazandağ M, Kazazoğlu E. A review on biodentine, a contemporary dentine replacement and repair material. Biomed Res Int 2014;2014:160951. DOI: 10.1155/2014/160951. 